\title{
Compradores de chismes y otras mercancías: las relaciones entre clientes y comerciantes importadores en Antioquia en la segunda mitad del siglo XIX*
}

\section{Resumen}

El comercio de importación en Antioquia durante la segunda mitad del siglo XIX se basó en el desarrollo de relaciones de confianza entre grandes importadores de mercancías y clientes, que eran a su vez pequeños y medianos negociantes distribuidores de los productos extranjeros. El artículo estudia las relaciones económicas entre comerciantes y clientes; se abordan las formas de compra y pago de bienes y los mecanismos sociales que servían para reforzar valores como el honor, la honradez y la confianza. La investigación, de carácter cualitativo, se sustenta, en lo primordial, en la correspondencia epistolar de los comerciantes Uribe Ruiz de Rionegro, Antioquia. Esta fuente permitió constatar cómo la circulación de información, las recomendaciones personales y las presiones sociales y económicas hacían parte de la cotidianidad del funcionamiento del mercado.

\section{Palabras clave}

Tesauro: Comercio, correspondencia, Colombia

Autor: importadores, clientes, Antioquia, siglo XIX, José María Uribe Uribe.

Referencia bibliográfica para citar este artículo: Mesa Bedoya, Ana María. "Compradores de chismes y otras mercancías: las relaciones entre clientes y comerciantes importadores en Antioquia en la segunda mitad del siglo XIX". Anuario de Historia Regional y de las Fronteras 26.2 (2021): 429-457.

Ana María Mesa Bedoya: Magister en Historia por la Universidad Nacional de Colombia. Investigadora del Grupo de Investigación en Historia Empresarial de la Universidad EAFIT. Profesora cátedra de Historia en la Universidad de Antioquia. Correo electrónico: ammesab@unal.edu.co. Código ORCID: 00000001.9450-4645.

\footnotetext{
* Este artículo hace parte de la tesis de maestría, con distinción Laureada, que la autora finalizó en el año 2019 en la Universidad de Nacional de Colombia, sede Medellín. No contó con financiación.
} 


\title{
Buyers of "Rumors" and Other Goods: Relations Between Customers and Importers in Antioquia in the Second Half of the Nineteenth-Century
}

\begin{abstract}
The import trade in Antioquia during the second half of the Nineteenth-century was based on the development of relationships of trust between large importers of goods and customers, who were in turn small and medium-sized business distributors of the foreign products. The article studies the economic relationships between merchants and customers; it addresses the forms of purchase and payment of goods and the social mechanisms that served to reinforce values such as honor, honesty, and trust. The research, of a qualitative nature, is based primarily on the epistolary correspondence of the merchants Uribe Ruiz de Rionegro, Antioquia. This source allowed us to see how the circulation of information, personal recommendations, and social and economic pressures were part of the daily operation of the market.
\end{abstract}

\section{Keywords}

Tesauro: Trade, Correspondence, Colombia.

Autor: Importers, Customers, Nineteenth-century, Antioquia, José María Uribe Uribe.

\section{Compradores de "fofoca" e outros bens: Relações entre clientes e importadores em Antioquia na segunda metade do século XIX}

\section{Resumo}

O comércio de importação em Antioquia durante a segunda metade do século XIX baseou-se no desenvolvimento de relações de confiança entre grandes importadores de mercadorias e clientes, que por sua vez eram pequenos e médios distribuidores comerciais dos produtos estrangeiros. $O$ artigo estuda as relações económicas entre comerciantes e clientes; aborda as formas de compra e pagamento de bens e os mecanismos sociais que serviram para reforçar valores tais como a honra, honestidade e confiança. A investigação, de natureza qualitativa, baseia-se principalmente na correspondência epistolar dos comerciantes Uribe Ruiz de Rionegro, Antioquia. Esta fonte permitiu-nos ver como a circulação da informação, recomendações pessoais e pressões sociais e económicas faziam parte do funcionamento diário do mercado.

Palavras-chave

Tesauro: Comércio, correspondencia, Colômbia.

Autor: importadores, clientes, século XIX, Antioquia, José María Uribe Uribe 


\section{Introducción}

El título del presente artículo podría prestarse a confusiones. Ciertamente, hasta ahora no se han encontrado en las fuentes del siglo XIX referencias sobre personas que compraran chismes, entendidos estos como una murmuración o una noticia falsa o verdadera. Los chismes, según el diccionario de la Real Academia de la Lengua Española, también son baratijas o trastos pequeños. ${ }^{1}$ El chisme y los chismes, con sus dos significados, hacían parte del habla común de la época referida. Como se verá a lo largo de este artículo, la compra y venta de mercancías no consistía en un mero intercambio mecánico y frío que se daba en el marco del mercado. El intercambio implicó el desarrollo de estrategias económicas y sociales que permitían acceder a información de todo tipo y a aplicar sanciones sobre comportamientos que pudieran afectar el progreso de los negocios comerciales.

La historia del comercio durante el siglo XIX en Colombia ha sido un tema de estudio recurrente. Se conocen mejor los casos de Antioquia, del Caribe colombiano, de la región de Santander y de otros lugares del centro y del sur del país. El mayor número de investigaciones en ciertas regiones se debe a que en ellas confluían uno o varios de los siguientes elementos: 1) la influencia en la vida económica, social y política de grupos de comerciantes y empresarios, 2) la configuración de mercados importantes para la venta de productos agropecuarios y de mercancías, 3) el funcionamiento de rutas mercantiles, 4) la explotación de productos valiosos para el mercado interno o externo y 5) la disponibilidad de fuentes.

Las investigaciones sobre el comercio han respondido a preguntas generales sobre las relaciones de poder político y socioeconómico que se forjaron en su seno, el desarrollo económico, de los transportes y del empresariado y de los inicios de la industria. Algunos problemas estudiados en relación con dichas preguntas han sido el papel de la familia, la figura del empresario, la constitución de sociedades comerciales, los tipos y el volumen de productos exportados e importados y la intervención o no del Estado en el sector comercial y de este en la esfera pública. ${ }^{2}$

\footnotetext{
${ }^{1}$ Alonso Valencia Llano, "El chisme y el escándalo en la sociedad colonial”, Estudios Sociales 3 (1988): 35-48. "Chisme" https://dle.rae.es/chisme?m=form (2020).

${ }^{2}$ Carlos Dávila, coord., Empresas y empresarios en la historia de Colombia, siglos XIX-XX: una colección de estudios recientes (Bogotá: Editorial Norma, 2003.) Rodrigo de Jesús García, coord., Élites, empresarios y fundadores: los casos de Antioquia y sur de Bolívar (Colombia), y el Tucumán colonial (Argentina) (Medellín: Universidad de Antioquia, Centro de Investigaciones de Ciencias Sociales y Humanas, 2003). María Mercedes Botero, La ruta del oro. Una economía primaria exportadora. Antioquia 1850-1890 (Medellín: Fondo Editorial Universidad EAFIT, 2007). Clara Inés Carreño, "Puertos locales y bienes de consumo: importación de mercancías finas en Santander, Colombia, 1870-1900", América Latina en la Historia Económica 22.1 (2015): 85-114. María Fernanda Duque Castro, "Comerciantes y empresarios de Bucaramanga (1857-1885): una aproximación desde el neoinstitucionalismo”, Historia crítica 29 (2005): 149-184. Adolfo Meisel, "Bajo el signo del cóndor: empresas y empresarios en el Caribe colombiano, 19822009”, ¿Por qué perdió la costa caribe el siglo XX? Y otros ensayos (Cartagena: Banco de la República, 2011), 287-310. Javier Mejía Cubillos, "Vínculos interregionales en la economía colombiana del siglo XIX: el empresariado de la costa Caribe en el interior del país, 1840-1880", Economía y Región 8.1 (2014): 197-201. Eduardo Posada Carbó, El caribe colombiano: una historia regional, 1870-1950 (Bogotá: Banco de la Republica, 1998.) Ana Milena Rhenals Doria y Francisco J. Flórez Bolívar, "Distintos sujetos bajo
} 
Compradores de chismes y otras mercancias: las relaciones entre clientes y comerciantes...

En términos generales, poco se conoce sobre las relaciones económicas que establecieron las personas que constituían una parte del mercado y quienes lo abastecían, es decir, clientes y comerciantes. En este artículo el término cliente se refiere al comprador de bienes, pues el consumidor no era quien compraba sino quien hacía uso final del producto. En efecto, en las fuentes consultadas se designaba como cliente a quienes compraban las mercancías. Los clientes eran tenderos o pequeños comerciantes que tenían crédito con grandes casas comerciales. Después de adquirir los productos, los distribuían entre los consumidores finales. Los comerciantes, según Beatriz Patiño Millán, Ann Twinam y María Teresa Uribe de Hincapié se clasificaban en pequeños, medianos y grandes de acuerdo con el valor en pesos y con la cantidad de las mercancías introducidas a sus mercados. ${ }^{3}$

Frank Safford, María Mercedes Botero y Ana María Otero-Cleves describen algunos aspectos sobre compradores y consumidores de mercancías en Bogotá y en algunos pueblos de Antioquia, como las preferencias de consumo, los plazos y los montos que pagaban por las mercancías, entre otros. ${ }^{4}$ Por su parte, algunos textos sobre la vida cotidiana proporcionan información valiosa; en Historia de la vida cotidiana en Colombia, varios historiadores precisan quiénes asistían a los mercados locales y cuáles productos podían adquirirse allí. ${ }^{5}$

A pesar de sus contribuciones, la bibliografía pertinente profundiza poco en las relaciones entre clientes y comerciantes. La materia resulta interesante para la investigación sobre procesos y actores con menos protagonismo en la historia escrita, como los compradores, que además de personas adineradas o que practicaban alguna profesión liberal, ubicadas en centros urbanos, también estaban constituidos

un mismo predicado: reflexión historiográfica sobre la historia empresarial en el Caribe colombiano", El Taller de la Historia III 3 (2011): 139-160. Frank Safford, "Commerce and Enterprise in Central Colombia, 1821-1870”, (Thesis, PhD, Columbia University, 1965). María Teresa Uribe de Hincapié y Álvarez, Jesús María, Raíces del poder regional: el caso antioqueño (Medellín: Editorial Universidad de Antioquia, 1998). Algunas de las últimas publicaciones sobre el tema son: María Virginia Gaviria y otros, Las sociedades civiles comerciales y de minas inscritas en los juzgados de Antioquia entre 1887 y 1934, una historia de la actividad societaria de la región (Medellín: Editorial Universidad EAFIT, 2020). Javier Mejía Cubillos, "Crecimiento económico de largo plazo en Antioquia, Colombia: Estimación del PIB. 1800-1913", Cuadernos de Economía 34-66 (2015): 507-544. Javier Mejía Cubillos, "El auge económico antioqueño del siglo XIX desde un enfoque de desarrollo económico local”, Ensayos de economía 45 (2014): 11-34.

${ }^{3}$ Beatriz Patiño Millán, "Los comerciantes de Medellín, 1763-1810”, Utopía Siglo XXI 2, no. 8 (2002): 111145. Ann Twinam, Mineros, comerciantes y labradores: las raices del espíritu empresarial en Antioquia: 1763-1810 (Medellín: Fondo Rotatorio de Publicaciones FAES, 1985). María Teresa Uribe de Hincapié, "Bajo el signo de mercurio: la influencia de los comerciantes de Medellín en la segunda mitad del siglo XIX”, RAED Revista Antioqueña de Economía y Desarrollo 30 (1989): 39-50.

${ }^{4}$ Safford, "Commerce and Enterprise in Central Colombia, 1821-1870." María Mercedes Botero, "Casas comerciales y circuitos mercantiles en Antioquia: 1842-1880," Revista Sociedad y Economía 12 (2007): 93114. Ana María Otero-Cleves, ““Jeneros de gusto y sobretodos ingleses” el impacto cultural del consumo de bienes ingleses por la clase alta bogotana del siglo XIX," Historia crítica 38, (2009): 20-45. Ana María Otero-Cleves, "Foreign Machetes and Cheap Cotton Cloth: Popular Consumers and Imported Commodities in Nineteenth-Century Colombia," Hispanic American Historical Review 97-3 (2017): 423-456.

${ }^{5}$ Patricia Londoño Vega, "La vida diaria: usos y costumbres", Historia de Antioquia, ed. Jorge Orlando Melo (Medellín: Suramericana de Seguros, 1988) 319-341. Beatriz Castro Carvajal, ed., Historia de la vida cotidiana en Colombia (Bogotá: Editorial Norma, 1996). 
por sectores populares de áreas urbanas y rurales. Otero-Cleves llama la atención acerca de la necesidad de estudiar diversos actores del siglo XIX, como campesinos, artesanos y pequeños propietarios desde la perspectiva de los patrones de consumo y no solo desde aquella de la fuerza de trabajo o bajo su dimensión política, como se ha hecho en forma tradicional. En el siglo XIX, las clases populares participaron de manera activa en el mercado de las mercancías extranjeras, tenían exigencias y gustos particulares y a través del consumo también formaron sus identidades. Como destaca la autora, para comprender el siglo XIX colombiano es necesario ver con nuevos ojos el papel de estos actores en la construcción de la nación. ${ }^{6}$

El objeto de estudio del artículo son las relaciones económicas entre clientes y comerciantes mayoristas en el contexto del mercado de bienes manufacturados importados. Los mercados agrícola y ganadero están por fuera del alcance de la investigación. Las relaciones cliente y comerciante hacen referencia a asuntos como las formas de compra, venta y pago de los bienes, la reputación social, la circulación de la información y varias acciones coercitivas.

La escasez de descripciones y análisis sobre las relaciones entre clientes y comerciantes se debe en parte a la falta de fuentes o al tratamiento que los investigadores han hecho de las disponibles. La contabilidad, por ejemplo, provee los nombres de los compradores, las mercancías adquiridas, los montos pagados y la frecuencia de las compras. Los documentos notariales, como compraventas, pagarés y fianzas o procesos judiciales también proporcionan información parecida.

En comparación, la correspondencia es más detallada pues brinda la posibilidad de adentrarse en el día a día de la actividad comercial. Pueden conocerse temas como las transacciones, las tensiones, las negociaciones, los pretextos, los prejuicios y otros. Por ejemplo, el 19 de mayo de 1890 Lucas Botero, de Sonsón (Antioquia), escribió a la casa comercial José María Uribe e Hijos de Rionegro (Antioquia) para dar cuenta del "negrito Fermín", a quien había recomendado para entrar en negocios con esa casa. Fermín no cumplió sus pagos y andaba "remontado" (escondido). Aunque Botero le advirtió que los Uribe iban "a hacerle muchos cargos con los cuales [podrían] arruinarlo", no logró "sacarle" el dinero, por lo que sentenció: "yo no lo recomiendo más pues en esta vez se manejó como la raza de donde viene que es africana". 7

La correspondencia es una fuente que permite comprender las dinámicas económicas más allá de los rasgos puramente cuantitativos. Además, resulta valiosa para el campo de la historia empresarial porque revela detalles de la cotidianidad de los negocios y de aspectos sociales del mundo cultural. En esta investigación se usó, en lo primordial, la correspondencia epistolar de una familia de comerciantes de Rionegro (Antioquia). José María Uribe Uribe (1807-1893) vendía mercancías

\footnotetext{
${ }^{6}$ Otero-Cleves, "Foreign Machetes" 423-456.

${ }^{7}$ Centro Cultural Biblioteca Luis Echavarría Villegas, Universidad EAFIT, Sala de Patrimonio Documental, Archivo José María Uribe Uribe (AJMUU), AJMUU-14, correspondencia recibida (CR), 1890, f. 54.
} 
nacionales y extranjeras compradas en Santa Marta, Bogotá y Medellín. A partir de 1855 y 1856, Uribe comenzó a importar bienes manufacturados de Francia, Gran Bretaña y Alemania, por lo que se convirtió en un gran comerciante importador. Aunque figuraba entre los mayoristas más importantes de Antioquia, su posición fue intermedia, pues los más grandes comerciantes de la época tenían más liquidez y se localizaban, por lo general, en Medellín. ${ }^{8}$

José María Uribe Uribe conformó en agosto de 1871 con sus hijos una sociedad comercial denominada José María Uribe e Hijos. ${ }^{9}$ La firma creció en clientela y almacenes y tenían uno en Rionegro (Antioquia) y otro en Manizales. Además, hacían viajes para vender en el Estado del Cauca. ${ }^{10}$ La sociedad comercial se fue modificando, de manera que en 1894 los socios Pedro y Estanislao Uribe Ruiz firmaron las escrituras de una nueva casa comercial, Uribe Ruiz Hermanos, que abrió una sede en Medellín en 1902 y hasta 1916 continuó abasteciendo el mercado cercano a Rionegro, Manizales y Medellín. Como la anterior sociedad, también era importadora mayorista, en especial de telas, hierro y acero. Asimismo, negociaba mercancías del país y exportaba oro y café.

Las casas comerciales José María Uribe e Hijos y Uribe Ruiz Hermanos son un caso de estudio representativo en Antioquia pues fueron sociedades de negocios importantes en la región. Hacia 1858, José María Uribe Uribe ya era reconocido como uno de los mayores introductores de mercancías de Rionegro. ${ }^{11}$ Además, entre 1880 y 1885, por ejemplo, la casa comercial José María Uribe e Hijos ocupó el puesto número 18 entre 427 empresas comerciales, instituciones y personas que pagaron más derechos de consumo por la importación de bienes extranjeros y nacionales en Antioquia. ${ }^{12}$ La estructura administrativa de las dos sociedades y su constitución se ajustan a la tendencia observada en Antioquia en el periodo; funcionaron como empresas familiares, y como grandes importadoras fueron ganando con el paso del tiempo un mayor número de clientes, en especial en el oriente y sur de Antioquia. Las características de estos clientes se evidenciarán a lo largo del texto.

El artículo se divide en cuatro secciones. En la primera se describe cómo era el mercado en el que vendían las mercancías los importadores. En la segunda se analizan los mecanismos de compra y venta de las mercancías. En la tercera se abordan temas como el desarrollo de relaciones de confianza y la importancia de tener una buena reputación en el mundo de los negocios. Finalmente, se esbozan las conclusiones.

\footnotetext{
${ }^{8}$ AHA, Fondo República, Hacienda Provincial de Antioquia, derechos de consumo, t 4079, 1880-1882; $\mathrm{t}$ 4087, 1883-1885.

${ }^{9}$ Circular enviada por José María Uribe e Hijos a Mamerto García Montoya, Bogotá, agosto $1^{\circ}$ de 1871. Biblioteca Nacional de Colombia, Archivo Mamerto García Montoya (AMGM), Documento RM 621 PZA. 41. Botero, "Casas comerciales," 106.

${ }^{10}$ Archivo Histórico Municipal de Manizales (AHMM), Fondo Notarial, Notaría 1, escritura 832, mayo 26 de 1875 , libro 18 , f. 543.

${ }^{11}$ Uribe, "Bajo el signo de mercurio," 43.

${ }^{12}$ AHA, Fondo República, Hacienda Provincial de Antioquia, Derechos de consumo, Tomos 4079 y 4087 , años 1880-1882, 1883-1885.
} 


\section{EI mercado}

[...] Mi querido Pepito y mi amigo don Rafael. Va para ese lugar el joven Juan de Jesús Londoño con el objeto de comprar a crédito unos chismesitos (sic). Si ustedes tienen a bien abrirle crédito en sus almacenes, pueden hacerlo en la inteligencia de que es muy honrado, muy juicioso, trabajador y económico, aunque pobre: Creo que la deuda que hagan en él es segura y garantizada solo con su buen manejo. Deseo se conserven bien y que manden a su sobrino y amigo afectísimo. Ignacio Uribe. ${ }^{13}$

Los pedidos de bienes mantenían en movimiento el negocio de importación: las compras constantes de pequeños y medianos clientes aseguraban la continuidad del flujo de mercancías. Las relaciones que los comerciantes tenían con los clientes partían del conocimiento personal o de recomendaciones sobre su liquidez y probidad, aunque por lo general había un documento legal que respaldaba la transacción de compra. Antes de adentrarse en las relaciones entre clientes y comerciantes es necesario establecer algunas características del mercado de aquella época.

Las actividades económicas que sustentaban la vida de Colombia en el siglo XIX eran la agricultura, la minería, la producción artesanal y el comercio, con menor o mayor intensidad en cada región. ${ }^{14}$ La mayor cantidad de población habitaba en los valles interandinos de clima templado y en los altiplanos de clima frío; con excepción del Caribe, en las tierras bajas y cálidas hubo menos población, como en los Llanos orientales y en la Amazonía. ${ }^{15}$ Hermes Tovar explica que entre 1800 y 1900 la colonización de la frontera del centro de Colombia ayudó a la formación de economías agrarias de "pan llevar", de pequeñas y medianas explotaciones de ganado y de empresas agrícolas y pecuarias. Entre estas unidades productivas se comerciaban diversos productos y eran ellas las proveedoras de centros de consumo más grandes. Además, hasta donde se congregaron los colonos llegaron "comerciantes con sus telas, sus herramientas y sus costureros para fortalecer y consolidar a innumerables familias". ${ }^{16}$

Sobre Antioquia, ${ }^{17}$ existe un consenso general sobre su éxito económico durante la segunda mitad del siglo XIX. La élite regional venía conformándose desde el período final de los Borbones (1780-1810). ${ }^{18}$ El aprovechamiento del oro les permitió a las élites darle dinamismo a la vida económica de la provincia, acceder a capitales importantes y controlar el poder político y económico. La organización de la explotación y la comercialización del mineral, además de la reinversión del capital

\footnotetext{
${ }^{13}$ Carta enviada por Ignacio Uribe desde Neira a los comerciantes José María Uribe e Hijos y Rafael Duque en Rionegro, 10 de octubre de 1887. AJMUU-9, CR, 1887, f.76.

${ }^{14}$ Marco Palacios y Frank Safford, Colombia, país fragmentado, sociedad dividida (Bogotá: Uniandes, 2011) 13-20.

${ }^{15}$ Palacios y Safford 14.

${ }^{16}$ Hermes Tovar Pinzón, Que nos tengan en cuenta. Colonos, empresarios y aldeas: Colombia 1800-1900 (Bogotá: Colcultura, 1995), 12.

${ }^{17}$ Hasta 1863 Antioquia fue un provincia. Luego, hasta 1886 fue un Estado. En adelante, un departamento.

${ }^{18}$ Carlos Dávila, El empresariado colombiano: una perspectiva histórica (Bogotá: Pontifica Universidad Javeriana, 1986) 119.
} 
en otras actividades productivas, ayudó al desarrollo de una mentalidad empresarial. ${ }^{19}$ Además, en Antioquia la negociación del oro en polvo entre pequeños productores y los comerciantes ayudó a dinamizar el sector comercial. Si bien el oro era uno de los productos de importación más relevantes del país, en Antioquia también se usaban para transacciones comerciales grandes y pequeñas.

María Teresa Uribe y Jesús María Álvarez explican que en Antioquia los comerciantes ricos "blancos" establecieron "relaciones mercantiles con una base social muy amplia en donde los matices de la piel pasaban a un segundo plano cuando el agente social podría ser un potencial vendedor o comprador". ${ }^{20}$ La existencia de una población que trabajaba de manera independiente y libre, como los mazamorreros (mineros libres), produjo el desarrollo de otro tipo de relaciones que aseguraban el control del producto regional más valioso: el oro. Al no existir un mecanismo extraeconómico cohesivo que asegurara la apropiación de ese producto, las estrategias más eficaces de control fueron el comercio y el crédito con una población negra, india y mestiza libre. ${ }^{21}$

El mercado antioqueño estuvo constituido por campesinos, pequeños y medianos propietarios, artesanos, personas que practicaban profesiones liberales y aquellas pertenecientes a las élites. Esta población se ubicaba en numerosos pueblos, que crecieron en número gracias al proceso de colonización iniciado a finales del siglo XVIII con varias etapas de desarrollo en el XIX. ${ }^{22}$ En ese proceso, una frontera agrícola abierta permitió el surgimiento de un campesinado pequeño y mediano más amplio. ${ }^{23}$ La concentración de la tierra en Antioquia fue menor que en Cauca y Cundinamarca. Además, el crecimiento poblacional antioqueño se destacó en el contexto nacional. ${ }^{24} \mathrm{El}$ número de habitantes fue aumentando a lo largo del siglo. Entre 1825 y 1835 se pasó de 104.253 a 158.017 personas. Luego, de 1843 a 1851, de 189.534 a 187.190 . Entre 1864 y 1870 , de 327.222 a 365.974 . Finalmente, entre 1883 y 1905 de 464.887 a $661.389 . .^{25}$

\footnotetext{
${ }^{19}$ Uribe y Álvarez 140.

${ }^{20}$ Uribe y Álvarez 49-55.

${ }^{21}$ Uribe y Álvarez 49-55.

${ }^{22}$ Tovar 77-80. Víctor Álvarez Morales, "Empresarios pueblerinos de Antioquia. El caso de José María "Pepe" Sierra S. 1846-1921", Élites, empresarios y fundadores. Los casas de Antioquia y sur de Bolívar (Colombia) y el Tucumán (Argentina), ed. Rodrigo García (Medellín: CISH-Colciencias, 2003) 197-252. Albeiro Valencia Llano, Colonización, fundaciones y conflictos agrarios Gran Caldas y Norte del Valle (Manizales: Artes Gráficas Tizán, 2000).

${ }^{23}$ Jorge Orlando Melo, "Historia de la población y ocupación del territorio colombiano" Colombia es un tema, septiembre de 1990, http://www.jorgeorlandomelo.com/histpobla.htm

${ }^{24}$ Tovar Pinzón 29.

${ }^{25}$ DANE, Panorama estadístico de Antioquia, siglos XIX y XX (Bogotá: Departamento Administrativo General de Estadística, 1981), 68-69. Carmen Eliza Flórez y Olga Lucía Romero, "La demografía de Colombia en el siglo XIX," en Economía colombiana del siglo XIX, Adolfo Meisel y María Teresa Ramírez (ed.) (Bogotá, Fondo de Cultura Económica, 2010), 384.
} 
Entre 1870 y 1883 se encuentra que en Antioquia la mayor parte de la población con oficio se dedicaba a la agricultura, la ganadería, las artesanías, el servicio doméstico y la minería. Se encontraban también comerciantes, arrieros, pescadores, empleados, sacerdotes, militares, institutores, legistas, médicos, ingenieros y fabricantes. ${ }^{26}$ Para Roger Brew, la capacidad de compra no era alta; en el área rural vivía un $80 \%$ de la población y sus ingresos eran bajos. ${ }^{27}$ Quienes tenían más ingresos se encontraban en los centros urbanos: pueblos como Medellín, Rionegro, Sonsón y Manizales tenían una mayor concentración de personas y actividades económicas o administrativas importantes. Lo mismo ocurría en centros mineros, como Titiribí, Santa Rosa, Frontino, Remedios, Amalfi y Segovia. ${ }^{28}$ Las clases altas podían darse una mejor vida que los campesinos, pero en todo caso no alcanzaban el lujo y la liquidez de las familias ricas de otros países. ${ }^{29}$ Sobre la economía de los campesinos antioqueños, un contemporáneo precisaba en 1885: "nuestros campesinos son bastante perseverantes para hacer frente á los obstáculos, y á pesar de fuertes dificultades, se logra arrancar del suelo lo preciso para satisfacer las necesidades más premiosas de la vida". ${ }^{30}$

Además de productos de origen nacional, en Colombia la población debía comprar artículos básicos y textiles extranjeros, pues la fabricación local era muy limitada. ${ }^{31}$ Otero-Cleves se muestra escéptica con la idea de que las clases con menos ingresos consumían pocos objetos importados. Durante el siglo XIX, campesinos, artesanos y pequeños propietarios compraron telas extranjeras baratas de algodón y otros objetos más finos para la agricultura, como el machete americano marca "Collins". ${ }^{32}$ La autora subraya que en un país rural "las importaciones estaban destinadas al consumo de mucho más que una pequeña población urbana”. Esto porque las pocas personas que componían las clases altas "del país no podían agotar completamente el suministro de la amplia gama de textiles y otros bienes de consumo traídos a Colombia desde Europa". ${ }^{33}$

Otero-Cleves plantea que, si bien los sectores populares tendían a comprar bienes baratos, también tenían exigencias en cuanto a calidad, colores y estilos. Si las preferencias no se cumplían, podían rechazar los artículos. ${ }^{34}$ Esta afirmación puede confirmarse en la correspondencia de los comerciantes Uribe Ruiz. El 15 de

\footnotetext{
${ }^{26}$ Marta Cecilia Ospina, "Un siglo de trabajo artesanal en Antioquia" (Tesis, Pregrado en Historia, Universidad de Antioquia, 1995) 29-38. Manuel Uribe Ángel, Geografía general del Estado de Antioquia en Colombia (Medellín: Autores Antioqueños, 1985) 11, 411. Tovar 38.

${ }^{27}$ Roger Brew, El desarrollo económico de Antioquia desde la Independencia hasta 1920 (Medellín: Editorial Universidad de Antioquia, 2000) 308.

${ }^{28}$ Brew 173. Londoño 320.

${ }^{29}$ Malcom Deas, "La política en la vida cotidiana republicana", Historia de la vida cotidiana en Colombia ed. Beatriz Castro Carvajal (Bogotá: Editorial Norma, 1996) 287.

${ }^{30}$ Uribe Ángel 476.

${ }^{31}$ Brew 266.

${ }^{32}$ Otero-Cleves, "Foreign Machetes" 430.

${ }^{33}$ Otero-Cleves, "Foreign Machetes" 431.

${ }^{34}$ Otero-Cleves, "Foreign Machetes" 433-435.
} 
septiembre de 1893, Severo Gutiérrez, de la Ceja (Antioquia), comprador regular de la firma José María Uribe e Hijos, se quejaba sobre la mala calidad y el alto precio de varias piezas de domésticas, bayetones y zarazas; de hecho, devolvía dos piezas de domésticas que habían salido mal. ${ }^{35}$

Las clases altas podían permitirse el consumo de textiles finos importados, objetos de lujo y alimentos fuera de lo común. El político y escritor José Eusebio Caro mencionaba en 1842 en una crítica sobre el lujo algunos productos que debían evitarse, como zapatos de raso con "lantejuelas", muebles de caoba, guisos, asados y vinos. ${ }^{36}$ Aunque Brew señala que la élite antioqueña no adquiría tantos artículos suntuosos como la bogotana, los comerciantes antioqueños sí importaban con regularidad decoración europea para sus casas y para vender. ${ }^{37}$ El cronista Juan de Dios Restrepo (Emiro Kastos) escribió sobre un baile al que había asistido en casa de un rico habitante de Medellín, Juan Pablo Sañudo, en 1855: “Agregad al natural encanto de una noche semejante bellos salones alfombrados, perfectamente iluminados i con ricos muebles...". ${ }^{38} \mathrm{Al}$ siguiente año, sobre una visita que hizo a Rionegro, apuntó: "En las casas de buena sociedad se encuentra tanta elegancia i cortesanía como en los mejores salones de Bogotá [...]. ${ }^{, 39}$ En efecto, Frank Safford explica que la imagen construida alrededor de los antioqueños ricos del siglo XIX como austeros, modestos y sencillos es exagerada. Tal apreciación provenía de la construcción de un mito útil para propagar los valores de la disciplina y el trabajo como bases para el triunfo económico. ${ }^{40}$

Los clientes de los comerciantes Uribe Ruiz se ajustan a la información antes anotada. Por una parte, proveían de mercancías a un mercado rural, de campesinos, y a una clase alta urbana. La correspondencia, así como una parte de la contabilidad, de las casas comerciales José María Uribe e Hijos y Uribe Ruiz Hermanos permitió identificar 845 clientes, repartidos entre los pueblos que se presentan en el tabla $n^{\circ} 1$, en orden de importancia según el número de compradores.

Los artículos que en mayor medida compraron los clientes fueron telas, hierro, acero, fósforos, papel, ropa y peroles. Adquirieron en menor medida licores, especias, enseres para la casa, instrumentos musicales, vidrios y armas. Hubo clientes que eran medianos y pequeños comerciantes, como Francisco Paneso, de Sonsón, quien entre 1887 y 1900 hizo compras que iban de \$300 a \$890. Paneso tenía un almacén desde el que abastecía a otros compradores del lugar. Si bien hacía pedidos de telas finas,

\footnotetext{
${ }^{35}$ AJMUU-23, CR, 1893, f. 46.

${ }^{36}$ J. E. Caro, "Sobre el lujo", El hombre honrado y laborioso, Sociedad de Beneficencia de Bogotá (Bogotá: Imprenta de J. A. Culla, 1842), 33.

${ }^{37}$ AJMUU-3, Correspondencia enviada (CE), 1863-1869, f. 9. AJMUU-25, CR, 1862-1885, ff. 3-9. AJMUU-102, CE, 1895-1896, ff. 236-237.

${ }^{38}$ Emiro Kastos, "Un baile en Medellín”, El Pueblo, 20, 28 de diciembre de 1855, Emiro Kastos, Colección de artículos escogidos (Bogotá: Imprenta de Pizano i Pérez, 1859), 165.

${ }^{39}$ Emiro Kastos, "Un paseo a Rionegro”, El Pueblo, 57, 21 de septiembre de 1856, Emiro Kastos, Colección de artículos escogidos (Bogotá: Imprenta de Pizano i Pérez, 1859), 224.

${ }^{40}$ Palacios y Safford 341-342.
} 
como la seda, también eran regulares las compras de dril. ${ }^{41}$ Los comerciantes mayoristas solían vender a este tipo de clientes bultos de mercancías; sin embargo, también hacían ventas más pequeñas a consumidores que requerían algunos artículos para uso propio. Por ejemplo, las cuatro ocasiones en las que Rafaela Herrera de Cali compró unas piezas de zaraza fantasía y coleta por valores modestos, de 5 reales a 8,4 pesos. $^{42}$

Tabla 1. Ubicación geográfica de los clientes de los comerciantes Uribe Ruiz, siglo XIX

\begin{tabular}{ll}
\hline Oriente de Antioquia & $\begin{array}{l}\text { Rionegro, La Ceja, El Retiro, El Peñol, Nariño, } \\
\text { Concepción, La Unión, Vahos, San Carlos, San Vicente, } \\
\text { Marinilla, Cocorná, Guatapé, Guarne, Santuario, El } \\
\text { Carmen, Llanogrande, San Rafael, Aquitania, San Luis, } \\
\text { Villeta, Nare y Alejandría }\end{array}$ \\
\hline Sur de Antioquia & $\begin{array}{l}\text { Sonsón, Manizales, Aguadas, Abejorral, Pácora, Salamina, } \\
\text { Neira, Pensilvania, Filadelfia y Aranzazu }\end{array}$ \\
\hline Estado del Cauca & $\begin{array}{l}\text { Cali, Cartago, Chocó, Riosucio, Santa Rosa, Villamaría, } \\
\text { Pereira, Palmira, Tuluá, Roldanillo, Pescador, } \\
\text { Buenaventura, Popayán, Santander, Filandia y Calarcá } \\
\text { Buga }\end{array}$ \\
\hline Otros lugares de Antioquia & Medellín, Girardota, Copacabana, Caldas, Itagüí \\
\hline Norte y nordeste de Antioquia & $\begin{array}{l}\text { Segovia, Remedios, Santo Domingo, Santa Rosa de Osos, } \\
\text { San Roque, Cacerí, Amalfi, Yolombó, Zea y Don Matías }\end{array}$ \\
\hline Occidente de Antioquia & Santa Fe de Antioquia, Frontino, Sopetrán \\
\hline Suroeste de Antioquia & Santa Bárbara, Jericó y Bolívar \\
\hline Otros lugares de Colombia & Bogotá, Manzanares y Ambalema \\
\hline
\end{tabular}

Fuente: Archivo José María Uribe Uribe, Universidad EAFIT

Francisco Paneso y Rafaela Herrera permiten caracterizar dos tipos de compradores. Se encuentra a los pequeños y medianos comerciantes y tenderos de los pueblos que constituían la principal base de los negocios mercantiles de los comerciantes mayoristas. Ellos ejercían el papel de agentes distribuidores. Una buena parte adquiría los bienes a crédito, pero también en consignación. Con esta última forma, el cliente tomaba productos para ofrecerlos en los pueblos y, después de vendidos, pagaba al gran comerciante. Sin embargo, en los casos de "ventas difíciles", porque los consumidores no se sentían satisfechos con la calidad o las características de las mercancías o por la mala situación económica que restringía el gasto de las familias, las mercancías eran devueltas al comerciante importador. Las casas comerciales José María Uribe e Hijos y Uribe Ruiz Hermanos prefirieron implementar la modalidad del crédito más que la de la consignación, pues con la primera la venta era segura, mientras que con la segunda las mercancías podían retornar a la casa comercial. Por otra parte, los comerciantes no desdeñaban las ventas al menudeo $\mathrm{y}$, aunque menos frecuentes, también se encuentra a este tipo de clientes.

\footnotetext{
${ }^{41}$ AJMUU-13, CR, 1889-1890, f. 70. AJMUU-14, CR, 1890, f. 24. AJMUU-5, CE, 1889-1892, f. 302.

${ }^{42}$ AJMUU-49, Libro borrador de diario, 1870-1883, ff. 22-23, 30.
} 
El médico Manuel Uribe Ángel apuntó que en el comercio antioqueño del siglo XIX se realizaban tres clases de operaciones: las compras realizadas en el exterior “... para la satisfacción de nuestras necesidades relativas a vestuario, comodidad y ornato, instrumentos para la minería y agricultura...", las compras hechas a otros Estados y el tráfico activo que se hacía en el interior. ${ }^{43}$ La mayor parte de las mercancías se traía de Europa debido a que la fabricación de bienes manufacturados no era común en el país. En un informe sobre Colombia del Bureau of the American Republics de los Estados Unidos de Norteamérica, del año 1892, se anotó al respecto:

La industria manufacturera es muy atrasada, y sólo produce azúcar, melaza, telas ordinarias de algodón y lana, algunos artículos de hierro, suela de cuero, sillas de montar, zapatos, muebles, sombreros de paja, joyas, barnices, libros, cerámica, esteras, bolsas, alfombras de hilo de maguey, cigarros, cigarrillos, brandy, ron, etc. En Antioquia las principales manufacturas son los sombreros de paja, hilados o seda torcida, vajilla (para cuya elaboración se ha establecido una fábrica en el distrito de Caldas), artículos de madera y hierro, y algunas clases de telas de consumo popular $[\ldots]{ }^{44}$

En Antioquia había un constante movimiento de oro, con el que podían hacerse compras regulares en el extranjero. ${ }^{45}$ Brew señala que la fuerte tendencia a la importación se debió "no tanto a la preferencia de los ricos por las mercancías europeas, sino al hecho de que la industria minera absorbía todo el excedente de mano de obra y no se desarrolló un sector artesanal productor de bienes de consumo." ${ }^{46} \mathrm{Si}$ bien el estándar de vida de gran parte de la población antioqueña era limitado, como en el resto de Colombia, el consumo era variable, con excepción de las telas, que por lo general se vendían en forma constante. ${ }^{47}$ La situación del consumo cambió en las dos últimas décadas del siglo, cuando la economía cafetera incidió en el crecimiento del mercado y en la capacidad de compra de los cultivadores. ${ }^{48}$

\section{Comprar y pagar mercancías}

Los artículos que adquirían las familias campesinas de áreas rurales y de los sectores urbanos debían comprarse en los mercados locales. Según Beatriz Castro, uno de los días más agitados de la semana durante el siglo XIX y principios del XX era el del mercado, "un evento similar al de la época colonial". ${ }^{49}$ Según Uribe Ángel, en Antioquia el comercio se hace en "ferias públicas, en tiendas, en campos, y tiene por objeto el repartimiento armónico de mercaderías, animales, víveres, instrumentos

\footnotetext{
${ }^{43}$ Uribe Ángel 475.

${ }^{44}$ Bureau of the American Republics, Colombia (Washington, bulletin No. 33, 1892) 77-78.

${ }^{45}$ Brew 267.

${ }^{46}$ Brew 266.

${ }^{47}$ Palacios y Safford 290.

${ }^{48}$ Brew 264-266, 273-274.

${ }^{49}$ Beatriz Castro, "La vida pública en las ciudades republicanas", Historia de la vida cotidiana en Colombia, ed. Beatriz Castro Carvajal (Bogotá: Editorial Norma, 1996) 256.
} 
de labor, y de todo lo que en síntesis, viene a manifestar el mantenimiento del Estado y la satisfacción de sus necesidades en todos los pormenores individuales". ${ }^{50}$

Los compradores de mercancías importadas o del país también adquirían los artículos de manera directa en los almacenes de las casas comerciales. Asimismo, los comerciantes iban por diversos pueblos ofreciendo los productos y tomando pedidos para luego enviarlos con un arriero. Además, un cliente podía mandar una carta en la que se listaban las mercancías, que después eran remitidas por el comerciante. Los costos de transporte los asumía el cliente. También el comprador podía enviar un mensaje con una persona autorizada para comprar los efectos. ${ }^{51}$

Las mercancías se adquirían de contado, en consignación o a crédito. El crédito era el mecanismo más usual. Por lo general, el dinero con el que pagaban los compradores dependía del producto que lograban de las cosechas, del pago de jornales o de la venta de oro y plata, por lo que la compra a plazos resultaba más conveniente. La fórmula más empleada para pagar a plazos era la de los tres seises: tres contados que se pagaban cada seis meses. Sin embargo, los comerciantes también otorgaron otras prórrogas. ${ }^{52}$ En 241 cuentas que la firma José María Uribe e Hijos abrió a 96 clientes de Cartago, Buga y Cali, entre 1870 y 1874, en la mayoría (89) se estableció "sin plazo fijo", en 39 con seis meses, en 27 con seis y seis meses, en 24 con cuatro meses, en 17 con tres meses y en el resto con otros plazos. ${ }^{53}$ En las cuentas sin plazo fijo se encuentran valores desde 5,4 reales hasta 2.873 pesos, este último una excepción, pues la mayoría de las cuentas sin plazo fijo (52) fueron por importes menores a $\$ 100$. Gregorio Velázquez, comerciante de Cali, recibió un crédito sin plazo fijo en marzo de 1872 por $\$ 2.324$ en mercancías. ${ }^{54}$ Dos años antes había comenzado con una cuenta por $\$ 60,3$. El valor de los otros 18 créditos que tuvo con José María Uribe e Hijos fue creciendo, por ejemplo, de \$439 a \$596,5, luego a $\$ 1.182,01$ y en 1873 a $\$ 2.873,01 .^{55}$

El tiempo otorgado para pagar los contados era flexible y dependía de la cantidad de mercancías y de su valor, de la confianza que se desarrollara entre las partes y de la situación económica y política del momento. Hay que apuntar que los comerciantes tomaban precauciones en coyunturas difíciles, pues sus finanzas se veían afectadas si los compradores no podían pagar como consecuencia de los trastornos que producían las guerras civiles o porque los medios de cambio eran afectados por las medidas que en materia de impuestos y moneda tomaban los gobiernos de turno. Por consiguiente, reducían los plazos de pago e, incluso, guardaban las mercancías para mejor ocasión. En el contexto de la guerra civil de 1885, que favoreció la

\footnotetext{
${ }^{50}$ Uribe Ángel 475-476.

${ }^{51}$ AJMUU-9, CR, 1887, ff. 58, 69, 75. AJMUU-107, CR, 1895-1896, f. 58.

52 Botero, "Casas comerciales," 108.

${ }^{53}$ AJMUU-49, borrador de diario, 1870-1873. AJMUU-48, borrador de diario, 1870-1874.

${ }^{54}$ AJMUU-49, borrador de diario, 1870-1873, f. 62.

${ }_{55}$ AJMUU-49, borrador de diario 1870-1873, ff. 7, 9, 12-13, 15-16, 20-21, 26, 29, 35, 42, 54, 61-62. AJMUU-48, borrador de diario, 1870-1874, ff. 25-26, 38, 47, 78, 86.
} 
llegada al poder del partido conservador, el comerciante Pedro Uribe Ruiz escribía a principios de 1886: “...todos los negocios los tenemos en suspenso”. El motivo era la incertidumbre que estaban viviendo por cuenta de un nuevo comparto ${ }^{56}$ impuesto a Antioquia por el presidente de la república, Rafael Núñez.

En época de incertidumbre, las ventas de mercancías continuaban, aunque con cautela. Otras variables eran consideradas para determinar el monto de los fiados y los plazos de pago, como la situación económica de los compradores, la cantidad de créditos que tenían e, incluso, su comportamiento privado. Cuando un comerciante necesitaba acceder a este tipo de información ponía en movimiento su red de conocidos, que incluía a amigos, familiares y otros clientes. Algunos de los temas expuestos por sus informantes giraban en torno a asuntos como la procedencia y el oficio de un comprador, la opinión que de él tenían en el comercio de la localidad en la que residía, si había recibido alguna herencia, cuáles propiedades tenía y cuál era su valor, si sí era verdad que algún insolvente estaba haciendo todo lo posible por pagar sus deudas, cuáles pueblos visitaba, cuáles eran sus condiciones de salud y en cuáles plazas de comercio compraba. ${ }^{57}$

No siempre los comerciantes daban el primer paso en la solicitud de información. Algunos allegados tomaban la iniciativa y advertían a sus colegas sobre circunstancias en las que estarían comprometidos sus intereses. Un cliente de Sonsón, llamado Ramón Gómez, advirtió a los comerciantes Uribe Ruiz en abril de 1885 que Juan C. Echeverri Uribe estaba vendiendo unas mercancías "ocultamente" y a menor precio, y terminaba: "Quizá usted en conocimiento de este asunto pueda salvar algo, pues me han dicho que también llevó géneros para la Ceja y sobre todo dinero. Ojalá mi aviso pueda serle de alguna utilidad" ${ }^{58}$ También el comerciante José María Arango, de Concepción, puso en alerta a José María Uribe en agosto de 1893 sobre los movimientos de Marco A. Carvajal:

[...] Ahora, lean ustedes el párrafo de una carta de uno de mis hijos, para lo que les convenga y deban obrar. Este dice: "Según comprendo, Carvajal pretende declararse en quiebra, y reservarse el dinero. Me parece muy conveniente que usted padre, en reserva, escriba a la Casa de los Señores José M. Uribe e Hijos de Rionegro dándoles cuenta del estado del sujeto ese, pues según creo a dichos señores les debe bastante, y como nosotros hemos cultivado tan buenas relaciones con ellos y les debemos muchos servicios, me parece de nuestro deber avisarles pronto". Si este aviso puede serles de alguna utilidad, lo celebraré. Inútil creo encargarles reserva alguna. ${ }^{59}$

\footnotetext{
${ }^{56}$ AJMUU-181, CR, 1885-1886, f. 75. El comparto consistía en una cantidad de dinero que debían pagar las personas con mayores ingresos o patrimonio, por lo general pertenecientes al bando contrario del que estaba en el poder, para financiar al Estado. AJMUU-181, CR, 1885-1886, ff. 7, 8, 23.

${ }^{57}$ AJMUU-3, CE, 1863-1869, ff. 11-12. AJMUU-8, CR, 1886-1887, f. 31. AJMUU-10, CR, 1887-1888, f. 23. AJMUU-20, CR, 1892, f. 85. AJMUU-104, CE, 1898-1900, ff. 31, 258. AJMUU-107, CR, 1895-1896, f. 19. AJMUU-109, CR, 1896, ff. 5, 35-36.

${ }^{58}$ AJMUU-180, CR, 1885, f. 4. AJMUU-180, CR, 1885, ff. 1-2, 7.

${ }^{59}$ AJMUU-23, CR, 1893, ff. 3-4.
} 
Ese mismo mes, Juan Bautista Uribe, empleado de los Uribe Ruiz en una finca cafetera en San Roque (Antioquia), escribió a Estanislao Uribe sobre las ventas de artículos que estaba haciendo Carvajal en esa población. ${ }^{60}$ Por supuesto, sobre todos estos informes se esperaba la mayor reserva, pues dadas las relaciones que mantenían los comerciantes entre sí y con los compradores no era conveniente generar recelos. ${ }^{61}$ Los ejemplos antes citados muestran que tener relaciones con personas de confianza en distintas poblaciones era fundamental para los comerciantes, pues la información que proporcionaba esta red servía para reducir la incertidumbre y acceder a datos valiosos para la toma de decisiones. De cualquier manera, estas medidas no eliminaban del todo el riesgo relacionado con el negocio.

También hay que añadir que la circulación de información entre los clientes fue usual, en especial la referida a los precios de los artículos, los plazos de pago, los intereses de los créditos y la calidad de los productos. No en pocas ocasiones los compradores reclamaban a los comerciantes sobre lo caro de una mercancía de la que sabían que había sido vendida más barata a otro cliente o sobre los pedidos de rebaja de precios porque otro comerciante ofrecía mejor calidad con costos más bajos. ${ }^{62} \mathrm{El}$ 27 de marzo de 1891, por ejemplo, Vicente B. Pérez, de San Vicente (Antioquia), un cliente regular de la casa José María Uribe e Hijos les escribió reclamando el plazo de pago que le habían hecho a Bernardino Jaramillo, otro cliente, y a no a él. Al respecto anotaba: "[...] Los plazos a que me refiero fueron 6 y 6 [meses] para Bernardino y solo 6 para mi $[\ldots]$ ". ${ }^{63}$

Para algunos compradores, pagar los créditos en persona era inviable por cuestiones de tiempo y dinero. En estos casos, los compradores preferían usar los servicios de una persona de confianza para transportar su dinero en vez del correo oficial. Es común encontrar referencias al respecto en la correspondencia comercial. Varios clientes se excusaron con los comerciantes Uribe Ruiz por no haber enviado sus contados a tiempo; explicaban que no era sencillo encontrar un portador de confianza. ${ }^{64}$ En la correspondencia se identificaron 337 personas que llevaron los pagos de clientes desde diferentes localidades de Cauca y Antioquia hasta Rionegro. ${ }^{65}$ Miguel Mejía, por ejemplo, en su camino de Pereira al oriente de Antioquia, recorría Manizales, Aguadas, Abejorral y La Ceja para terminar en el almacén de los Uribe en Rionegro. ${ }^{6}$ Esta era otra ventaja que ofrecía la red comercial: apoyarse en diferentes

\footnotetext{
${ }^{60}$ AJMUU-197, CR, 1893-1894, ff. 20.

${ }^{61}$ AJMUU-104, CE, 1898-1900, f. 31. AJMUU-118, CR, 1904-1913, f. 2.

${ }^{62}$ AJMUU-8, CR, 1886-1887, f. 65. AJMUU-5, CE, 1889-1892, ff. 40-41. AJMUU-14, CR, 1890, f. 102. AJMUU-15, CR, 1890, f. 11. AJMUU-16, CR, 1890-1891, f. 81. AJMUU-115, CR, 1900, ff. 82-83.

${ }^{63}$ AJMUU-16, CR, 1890-1891, f. 81.

${ }^{64}$ AJMUU-12, CR, 1889, ff. 57-58. AJMUU-18, CR, 1891, f. 70. AJMUU-20, CE, 1892, f. 25. AJMUU-13, CR, 1889-1890, f. 73. AJMUU-14, CR, 1890, f. 2. AJMUU-111, CR, 1898, f. 7.

${ }^{65}$ AJMUU-5, CE, 1889-1892, f. 31. AJMUU-188, CR, 1890-1891, f. 12. AJMUU-15, CR, 1890, f. 99. AJMUU-16, CR, 1890-1891, f. 25. AJMUU-104, CE, 1898-1900, f. 82. AJMUU-21, CR, 1893, f. 5. AJMUU-102, CE, 1895-1896, f. 115, 129. AJMUU-103, CE, 1897-1898, f. 1. AJMUU-104, CE, 1898-1900, f. 82. AJMUU-107, CR, 1895-1896, f. 32. AJMUU-115, CR, 1900, f. 1. AJMUU-13, CR, 1889-1890, f. 69.

${ }^{66}$ AJMUU-6, CR, 1875-1884, f. 25. AJMUU-8, CR, 1886-1887, f. 66. AJMUU-5, CR, 1889-1892, ff. 7,
} 
agentes que permitían la movilización de las mercancías y el dinero, además de la consecución de información.

Contar con una persona honrada y responsable que movilizara el dinero era fundamental, pues podía ocurrir que el encargado usara los fondos en forma indebida, que no los entregara a tiempo o que se equivocara de casa comercial, con lo que los intereses por incumplimiento empezaban a correr. ${ }^{67}$ Esto le ocurrió a Segundo Henao, de Sonsón: en su intento por hacerle llegar a Uribe Ruiz Hermanos \$506 en 1898, recurrió a los servicios de Miguel J. Mejía. Este, sin consultarle a Henao, le entregó el dinero a Lisandro Jaramillo para que lo llevara a Rionegro, pero Jaramillo se lo dio, a su vez, a Julio Tobón, quien en últimas solo entregó \$406. Segundo Henao se excusaba recordando a los Uribe Ruiz "lo trabajoso que es encontrar con quien remitir dinero tanto para esa [Rionegro] como para Medellín", ${ }^{68}$

Ahora bien, las operaciones de pago no solo consistían en la entrega de dinero en moneda corriente. Hubo otras maneras de saldar las cuentas, consecuencia de las dificultades que presentaron la movilización del dinero, el desordenado sistema monetario y las crisis económicas. De acuerdo con María Mercedes Botero, hubo trueque y pagos en especie en Antioquia durante la segunda mitad del siglo XIX. Si bien el oro y la plata circularon como moneda, en algunas ocasiones escasearon, en especial el oro, que era exportado a Europa. A partir de la década de 1870, los bancos privados ofrecieron billetes al portador (promesas de pago a la vista), hecho que benefició al comercio. No obstante, en 1886, el establecimiento del papel moneda de curso forzoso, del Banco Nacional, generó una crisis monetaria porque estaba permanentemente depreciado. Además, el país atravesaba desde comienzos de los años ochenta dificultades económicas por causa de una baja en las exportaciones, con su consecuente déficit comercial y fiscal, a lo que se sumaba la falta de circulante. ${ }^{69}$

Debido a estos factores, los compradores implementaron otras formas de pago. Entre ellas, el uso de la letra de cambio, que era de más seguro transporte por correo y facilitaba las transacciones de comercio. En mayo de 1864, por ejemplo, Joaquín Mejía, de Santa Bárbara (Antioquia), giró una letra en contra de José María Arango y Federico Orozco, de Rionegro, a quienes había vendido un tabaco, y a favor de José María Uribe Uribe, para pagar una obligación comercial. Entonces, Mejía obtenía el pago de su cacao, no tenía que enviar dinero por el correo ni con un portador y cubría su contado a Uribe..$^{70}$ El uso de la letra era beneficioso para aquellos que se encontraban separados

264. AJMUU-23, CR, 1893, ff. 15, 81. AJMUU-24, CR, 1894-1896, f. 13. AJMUU-102, CE, 1895-1896, ff. 19, 370. AJMUU-105, CR, 1893-1895, f. 83. AJMUU-108, CR, 1896, f. 26. AJMUU-115, CR, 1900, ff. $11,88-89$.

${ }^{67}$ AJMUU-1, CE, 1853-1857, ff. 52-53. AJMUU-12, CR, 1889, f. 89. AJMUU-5, CE, 1889-1892, f. 303.

${ }^{68}$ AJMUU-113, CR, 1899, ff. 8-9, 13, 32.

${ }^{69}$ Botero, La ruta del oro 19, 30-31, 80, 153, 157, 159, 238-239.

${ }^{70}$ AJMUU-179, CR, 1853-1885, f. 8. AJMUU-49, Libro borrador de diario, 1870-1883, f. 48. AJMUU-6, CR, 1875-1884, ff. 24, 39, 67. AJMUU-8, CR, 1886-1887, ff. 30, 39, 45. AJMUU-9, CR, 1887, ff. 3, 39. AJMUU-11, CR, 1889, ff. 16, 94 AJMUU-186, CR, 1888-1889, f. 51. AJMUU-13, CR, 1889-1890, f. 99. AJMUU-16, CR, 1890-1891, f. 23. AJMUU-18, CR, 1891, f. 35. AJMUU-19, CR, 1892, f. 57. AJMUU-22, 
por grandes distancias de las casas comerciales. Próspero Roldán, de Tuluá (Cauca), enviaba una letra a cargo de un intermediario en Manizales que, a su vez, giraba otra en contra de algún vecino de Rionegro para pagar sus deudas. ${ }^{71}$

Ahora bien, varios compradores encontraron dificultades en la obtención de letras, moneda o billetes porque escaseaban. También porque los clientes no siempre tenían suficiente dinero. ${ }^{72}$ Estas difíciles circunstancias los llevaban a responder por sus obligaciones de otra manera. Entre ellas, enviando cerdos y ganado a Medellín y Rionegro para que un tercero los vendiera y con el producido pagar en las casas comerciales. $^{73}$ Una carta de enviada desde Salamina el 31 de agosto de 1898 por Jesús Peláez R., a la casa Uribe Ruiz Hermanos en Rionegro, ilustra la situación:

Estimados señores y amigos: Como el señor Siseto Rivera llevó unos cerdos gordos para realizarlos por mi cuenta y le ordené que me le dejara allá el contado de este mes, el Señor Rivera me manifestó aquí que le había vendido los cerdos a Dn. Indalecio ó á Dn. Agustín Tobón y que dichos Señores 1 darían la suma á los ocho días y hasta la fecha no sé si habrán cubierto el dinero, háganme el favor de comunicarme lo mas pronto que les sea posible $[\ldots]{ }^{74}$

También había pagos en especie. Aunque los comerciantes preferían la moneda corriente, solían recibir productos como cacao, mulas, café, maíz y anís, para asegurar una parte del dinero. En diciembre de 1899, la firma Uribe Ruiz Hermanos increpaba a José María Arcila, de El Peñol (Antioquia): "Díganos cuánto café tiene, de qué clase es y a cómo nos lo da para abonar su valor a la cuenta suya, pues como ya le hemos manifestado estamos urgidos de dinero y no podemos aguardar indefinidamente que usted nos pague sus contados vencidos". ${ }^{75}$

\section{La confianza y la buena reputación}

La confianza fue un elemento fundamental para establecer el comercio como actividad económica rentable. De acuerdo con Javier Lamikitz, la confianza y la reputación han sido más estudiadas por sociólogos, antropólogos y economistas; aunque la reputación ha sido más abordada por los historiadores. El autor señala la incidencia de la falta de información y los altos grados de riesgo en el comercio de larga distancia como factores que llevaron a la formación de relaciones de confianza en el mundo comercial. En suma, afirma que la confianza facilitaba los intercambios económicos y sociales. Además, la confianza y la reputación eran mecanismos que ayudaban a la reducción de riesgos. ${ }^{76}$

\footnotetext{
CR, 1893, f. 9.

${ }^{71}$ AJMUU-20, CR, 1892, f. 68.

${ }^{72}$ AJMUU-6, CR, 1875-1884, f. 39. AJMUU-16, 1890-1891, f. 63. AJMUU-21, CR, 1893, f. 84.

${ }^{73}$ AJMUU-114, CR, 1899, f. 34. AJMUU-116, CR, 1900-1901, f. 107.

${ }^{74}$ AJMUU-112, CR, 1898, f. 23.

75 AJMUU-104, CR, 1898-1900, f. 476. AJMUU-49, Libro borrador de diario 1870-1883, ff. 1, $39,67$. AJMUU-194, CR, 1889-1890, f. 84. AJMUU-197, CR, 1893-1894, f. 40. AJMUU-104, CE, 1898-1900, f. 111.

${ }^{76}$ Xabier Lamikiz, "Un “cuento ruidoso": confidencialidad, reputación y confianza en el comercio del siglo
} 
En Colombia, en la estructura de relaciones mercantiles del siglo XIX, en un contexto de serias dificultades institucionales y económicas, se constituyó un mundo de valores culturales en torno a los negocios; estos valores soportaron el desarrollo del comercio. Varios mecanismos legales y sociales se pusieron en práctica para reforzar el honor, la responsabilidad, la honradez, la confianza y la buena reputación. A continuación, se describe a través de algunos casos de clientes cuyas conductas contradecían dichos valores cómo los comerciantes trataban de proteger sus intereses.

Si bien comerciantes y clientes acordaban los plazos de pago, el sistema no era rígido, pues los compradores podían demorar unos días el envío de sus contados por la dificultad para conseguir un portador de confianza para las letras de cambio o la moneda corriente. Los clientes explicaban los motivos de su atraso y solicitaban tiempo que, en caso de ser concedido, implicaba cubrir intereses por mora. En la correspondencia de los comerciantes Uribe Ruiz se hallaron 304 cartas con estas solicitudes; entre las explicaciones se encuentran, entre otras, enfermedades que impiden trabajar o que afectan a un familiar, malas ventas, incumplimiento de pago de los fiados, robo de mercancías, incendio del almacén en que vendían, las condiciones del clima que dañaban las cosechas con las que planeaban cubrir parte de las deudas, muchos acreedores “encima” y, en su mayoría, la mala situación económica. ${ }^{77}$

Estas cartas también permiten observar que los clientes, pequeños y medianos tenderos o propietarios de parcelas, se dedicaban a otros negocios, con los que respondían ante un eventual problema en la venta de mercancías. Dichos negocios incluían, entre otros, la venta de productos agropecuarios, la explotación de una mina o la venta de alguna propiedad. ${ }^{78}$ Así lo manifestaba en noviembre de 1898 Andrés Díaz, de Nariño (Antioquia), a la firma Uribe Ruiz Hermanos. Díaz confirmaba que había recibido una carta en la que Uribe le decía que debía enviar dinero con frecuencia para estar "contento" con él. Para cubrir sus deudas aseguraba que vendería un derecho en una mina y un café que tenía en Honda. Además, proponía hipotecar "unas finquitas" y esperaba que tuvieran un poco de paciencia y no desconfiaran de él. ${ }^{79}$ Michael F. Jiménez describe que campesinos, pequeños propietarios y peones en la Colombia rural del siglo XIX se dedicaban a múltiples tareas, de las que conseguían el sustento familiar. Trabajaban sus propias tierras o las de las haciendas, vendían "granos, frutas y vegetales" cada mes en el mercado local, hacían trabajos temporales en sus casas de habitación o lejos de ellas, buscaban la explotación de minas; en suma, combinaban "la producción de alimentos básicos, ganados y manufactura doméstica artesanal" ${ }^{80}$ Aventurarse en la venta de mercancías que compraban a mayoristas y medianos comerciantes se constituía en otro medio para ganar dinero.

\footnotetext{
XVIII", Obradoiro de Historia Moderna 16 (2007): 113-142. DOI: 10.15304/ohm.16.541

${ }^{77}$ AJMUU-180, CR, 1885, f. 3. AJMUU-182, CR, 1886, ff. 30, 36, 38. AJMUU-9, CR, 1887, f. 84. AJMUU-194, CR, 1889-1890, f. 13. AJMUU-13, CR, 1889-1890, f. 54. AJMUU-18, CR, 1891, f. 27. AJMUU-20, CR, 1892, f. 65. AJMUU-107, CR, 1895-1896, f. 28. AJMUU-115, CR, 1900, ff. 57, 62.

${ }^{78}$ AJMUU-14, CR, 1890, f. 86. AJMUU-18, CR, 1891, ff. 33, 36-37. AJMUU-107, CR, 1895-1896, f. 61. AJMUU-114, CR, 1899, ff. 12-13, 80. AJMUU-115, CR, 1900, f. 4. AJMUU-271, CR, 1873-1893, f. 104.

${ }^{79}$ AJMUU-112, CR, 1898, ff. 84-85. AJMUU-115, CR, 1900, f. 50.

${ }^{80}$ Michael F. Jiménez, "La vida rural cotidiana", Historia de la vida cotidiana en Colombia, ed. Beatriz Castro Carvajal (Bogotá: Editorial Norma, 1996) 163-170.
} 
Los comerciantes concedían prórrogas de pago, que iban desde 15 a 20 días, dos meses o hasta seis, pues preferían recibir el dinero en vez de proceder judicialmente (lo que podía significar demoras y gastos) o tomar propiedades hipotecadas en las que no estaban interesados. José María Uribe e Hijos se lo explicaba a Juan Osorno, de Girardota (Antioquia), en mayo de 1890, ante la propuesta del fiador de pagar su deuda con tierra: "Como a nosotros no nos conviene recibir fincas raíces a ningún precio, vamos a notificarle a usted que si no nos hace el pago en dinero de lo que nos debe o por lo menos de una parte considerable, lo ejecutaremos a usted y le anularemos las ventas de fincas que ha hecho y todas las demás operaciones hechas estando en mora" ${ }^{81}$ Cuando en definitiva los clientes no cumplían sus obligaciones, los comerciantes recurrían a varios mecanismos para salvar sus intereses.

Varios especialistas en historia económica han llamado la atención sobre el papel de las instituciones formales e informales en el funcionamiento del comercio a larga distancia. Una discusión importante es la planteada por Jeremy Edwards, Sheilagh Ogilvie y Avner Greif para el caso de los comerciantes magrebíes del siglo XI. De acuerdo con los dos primeros autores, el sistema legal era el principal fundamento de las relaciones entre los comerciantes y sus agentes, mientras que Greif señala la importancia de otros mecanismos que tenían un rol definitorio, como los de la reputación multilateral. ${ }^{82}$ Este mecanismo consistía en la existencia de un "contrato implícito" del que eran conscientes los comerciantes y los agentes que los representaban en mercados distantes. Dicho contrato implicaba que los agentes que hubieran estafado a un integrante del grupo serían rechazados por otros comerciantes. Los mercaderes usaban sus redes comerciales y sociales para hacer pública la estafa y afectar la reputación de los implicados, operaba, entonces, un castigo multilateral. Asimismo, Greif apunta que la organización de las relaciones de intercambio a lo largo de la historia respondió a "la necesidad de hacer cumplir los contratos", en especial, cuando las instituciones formales no podían hacerlos efectivos. ${ }^{83}$ Aunque las relaciones que estudia este artículo son las de los comerciantes con sus clientes y no la de los comerciantes con sus agentes, es interesante notar que también aquí se evidencian algunos mecanismos en los que la reputación era usada para hacer cumplir los pagos de las obligaciones.

La evidencia empírica muestra que los comerciantes usaban los dos mecanismos, el legal y el informal. Así, a pesar de que los Uribe Ruiz actuaban en un marco institucional inestable, expresado en las exacciones sobre mercancías, ganados e impuestos y la prisión y el ocultamiento en época de guerras civiles, ellos hacían uso de instituciones formales representadas en un sistema legal (códigos de comercio), pero también de instituciones informales (normas e ideas), todo ello con el propósito de presionar a los clientes incumplidos. Cuando los compradores estaban atrasados o

\footnotetext{
${ }^{81}$ AJMUU-5, CE, 1889-1892, f. 122. AJMUU-11, CR, 1889, f. 86. AJMUU-21, CR, 1893, ff. 57-58.

${ }^{82}$ Avner Greif, "Contract Enforcement and Institutions among the Maghribi Traders: Refuting Edwards and Ogilvie", $\operatorname{SSRN}$ (2008): 1-30. https://ssrn.com/abstract=1153826 or http://dx.doi.org/10.2139/ssrn.1153826

${ }^{83}$ Avner Greif, "Teoría de juegos e historia de la empresa", Historia empresarial 812 (2004): 9-26. http:// ebour.com.ar/ensayos_meyde/Avner\%20Greif\%20-\%20Teoria\%20de\%20Juegos\%20e\%20Historia\%20 de\%201a\%20Empresa.pdf
} 
se negaban a cancelar sus deudas, eran advertidos sobre la posibilidad de "ejecutarlos" o hacerles una "ejecución", lo que significaba recurrir a la justicia. En septiembre de 1889, Cayetano Echeverri, de Abejorral (Antioquia), le suplicaba a José María Uribe e Hijos que le dieran más tiempo, que vendería unas fincas para cumplir y pedía que no lo mandaran a ejecutar. Esperaba también que en su pueblo no se dieran cuenta de que estaba en apuros, pues aprovecharían la situación para ofrecerle menos por las fincas. ${ }^{84}$

Para proceder a una ejecución, el comerciante debía contar con pruebas, como correspondencia, libranzas, pagarés o contratos. ${ }^{85}$ Cuando un comprador tomaba mercancías, además de la factura se le remitía el "documento", es decir, libranzas y pagarés, que servían de garantía. Esta práctica se llevó a cabo durante todo el siglo por pequeñas y grandes cantidades. En una muestra de 99 documentos, que van de 1838 a 1906 , se hallan valores desde $\$ 40$ hasta más de $\$ 2.500$. Según el Código de Comercio de 1853 de Colombia, estos documentos eran promesas de pago sujetas a las leyes sobre préstamos. Se redactaban en papel sellado y especificaban fecha, cantidad adeudada, época de pago, la persona a la que se debía y su lugar de residencia, el origen y la especie del valor que representaba (mercancías, dinero, propiedades), las firmas de las partes y las de algunos testigos. Se establecía que no habría demora en los pagos y que, en caso contrario, el deudor correría con los costos de la cobranza judicial o extrajudicial que correspondiera. ${ }^{86}$

Ahora bien, antes de proceder por intermedio de la justicia, los comerciantes trataban de persuadir a los clientes morosos para que cumplieran sus compromisos. En sus cartas, los comerciantes subrayaban la confianza que habían depositado en ellos y que no debía ser defraudada, esperaban equidad y justica, apuntaban que ya habían tenido muchas consideraciones especiales, pero que no podían seguir los dictados del corazón, sino los de sus intereses, sabían que los deudores tenían dinero, deseaban no hostilizarlos y, para terminar, les advertían por última vez en forma amigable para no tener que tomar medidas desagradables. ${ }^{87}$

Los clientes también eran presionados a través de las personas que los habían recomendado o con sus familiares. Las recomendaciones eran importantes para entrar en negocios con las casas comerciales. De acuerdo con Albane Forestier, las recomendaciones personales servían para formar nuevos lazos de negocios y eran herramientas esenciales para la afirmación de la reputación y el carácter de un

\footnotetext{
$\overline{{ }^{84} \text { AJMUU-12, CR, 1889, ff. 71-72. }}$

${ }^{85}$ AJMUU-12, CR, 1889, f. 66. AJMUU-17, CR, 1891, ff. 94-95.

${ }^{86}$ Colombia, Código de comercio: 1 de junio de 1853 (Bogotá: s.e, 1853) lxxix-lxxxi. AJMUU-260-262, familia Uribe Ruiz. Pagarés, libranzas, compraventas, contratos seguros, 1843-11906. AHMM, Fondo notarial, Notaría 1, escr. 649, octubre 31 de 1879, libro 24, f. 649; escr. 308, agosto 14 de 1880, libro 26, f. 78; escr. 593, marzo 7 de 1881, libro 27, f. 265; escr. 1332, septiembre 22 de 1883, libro 31, fs. 732-734; escr. 235, abril 19 de 1884, libro 32, f. 580; escr. 465, agosto 2 de 1884, libro 33, f. 159; escr. 557, octubre 15 de 1886, libro 36, f. 457; escr. 921, enero 1 de 1888, libro 41, f. 12.

${ }^{87}$ AJMUU-3, CE, 1863-1869, ff. 121-122, 198, 211, 238, 322-323. AJMUU-5, CE, 1889-1892, ff. 259-260, 398. AJMUU-102, CE, 1895-1896, ff. 42, 291, 293, 318, 331, 337. AJMUU-118, CR, 1904-1913, f. 4.
} 
individuo. ${ }^{88}$ Como la misma autora afirma, había otros mecanismos para comenzar una nueva relación, entre ellos comprobar, a través de información de terceros, la "situación" de una persona, esto es, su capacidad económica, sus conexiones, etc. En las cartas de recomendación recibidas por los comerciantes Uribe Ruiz se evidencia que quienes las escribían se hacían responsables por el crédito del recomendado, además de referirse a cualidades como la honradez, el trabajo duro, la responsabilidad y la buena aceptación que tenía la persona en mención. ${ }^{89}$

Sin embargo, una recomendación o la información recabada sobre un cliente potencial no eran garantías infalibles acerca de su futuro comportamiento financiero. Cuando los compradores que habían sido recomendados por un tercero fallaban en el pago de sus créditos, los comerciantes reclamaban a quienes los habían introducido, como a Luis María Botero de Medellín, quien en 1884 presentó a Juan C. Echeverri a la firma José María Uribe e Hijos como honrado y competente y dio su palabra de "caballero" de que era un buen marchante. De acuerdo con la correspondencia, Uribe se reprochaba haber confiado en la firma de Botero en esta recomendación, pues habían abierto a Echeverri una cuenta por $\$ 1.000$ que no cubrió. Al siguiente año, Botero se lamentaba sobre lo ocurrido y se comprometía a hablar o a escribirle a Echeverri para que pagara. ${ }^{90}$

La comunicación con los padres del moroso también podía surtir algún efecto. En agosto de 1891, José María Uribe e Hijos escribió a José María Rodas, de Aguadas, cliente desde 1868, para informar que su hijo, Lisandro Rodas, les debía una fuerte suma. Según noticias que tenían, Lisandro estaba repartiendo sus bienes para pagarles a varios acreedores, menos a ellos. Por tal motivo le escribían, para que lo influenciara y no cometiera tan "marcado desfavor". Unos días después, Lisandro cubrió una parte de su deuda en Manizales y les pidió que no "apretaran” a su papá que él sí iba a pagar."1

Por último, debe agregarse que los clientes eran conscientes de la mala situación que pasarían si llegaban a una ejecución, lo que incluía la pérdida de propiedades hipotecadas y las represalias contra sus fiadores. Además, los comentarios desfavorables sobre su reputación resultarían inconvenientes para la realización de futuros negocios. Así, Andrés Díaz, de Nariño (Antioquia), suplicaba en octubre de 1898 a Uribe Ruiz Hermanos que no lo ejecutaran pues "lo hundirían para siempre en el abismo de la miseria y del infortunio". ${ }^{92}$

\footnotetext{
${ }^{88}$ Albane Forestier, "Risk, kinship and personal relationships in late eighteenth-century West Indian trade: The commercial network of Tobin \& Pinney" Business History 52.6 (2010): 919.

${ }^{89}$ AJMUU-6, CR, 1875-1884, f. 66. AJMUU-261, Familia Uribe Ruiz. Pagarés, libranzas, compraventas, contratos seguros, 1860-1888, f. 28. AJMUU-7, CR, 1885-1886, ff. 13-14, 52. AJMUU-9, CR, 1887, ff. 42-43, 46-47. AJMUU-184, CR, 1887, f. 105. AJMUU-10, CR, 1887-1888, f. 27. AJMUU-11, CR, 1889, f. 32. AJMUU-16, CR, 1890-1891, f. 50. AJMUU-19, CR, 1892, f. 39. AJMUU-22, CR, 1893, f. 40. AJMUU-110, CR, 1897-1898, f. 32. AJMUU-115, CR, 1900, f. 76.

${ }^{90}$ AJMUU-261, Familia Uribe Ruiz. Pagarés, libranzas, compraventas, contratos seguros, 1860-1888, f. 28. AJMUU-7, CR, 1885-1886, ff. 1-2.

${ }^{91}$ AJMUU-5, CE, 1889-1892, f. 437. AJMUU-18, CR, 1891, f. 7.

${ }^{92}$ AJMUU-112, CR, 1898, ff. 45-46.
} 
En un folleto de 1842 dedicado a quienes se presentaron a la segunda exposición de los productos de la industria de Bogotá, se encuentra la reproducción de un texto, firmado por Delamétherie, que promovía el honor y el buen crédito como valores esenciales para realizar cualquier oficio o industria que sirviera al público. Sobre la reputación se lee:

[...] La buena reputación es el primer bien del hombre social, pero es mas delicada que la luna de un espejo: el mas lijero vapor la empaña, y es necesario no solo conservarla cuidadosamente, sino limpiarla todos los dias para que aparezca cada vez mas brillante. - J. M. Galvis. Por honor se entiende esa flor de la reputación que no sufre mancha. El hombre de honor no debe tener nada que reprocharse, porque el mundo no le perdona la falta más lijera. El honor del comerciante sufre si deja protestar una vez sus libramientos $[\ldots] .^{93}$

La reputación, la confianza y la confidencialidad en el mundo comercial eran fundamentales. Javier Lamikiz ha estudiado con amplitud el tema para el comercio del siglo XVIII. ${ }^{94}$ De acuerdo con el autor, la incertidumbre que generaban las grandes distancias y la precariedad de la comunicación, entre otros factores, se traducían en altos riesgos. Para lidiar con estos problemas, los comerciantes contaban con la reputación y la confianza como mecanismos de reducción de riesgos. ${ }^{95}$ A pesar de la existencia de dispositivos legales, que servían para sancionar las malas conductas, la realización de negocios se sustentaba, sobre todo, en un acto de fe. ${ }^{96}$ Por supuesto, este acto de fe se amparaba en la información. Sobre las quiebras, Lamikiz explica que una declaratoria de tal naturaleza no era conveniente, pues podían desencadenarse muchos problemas de orden jurídico, como otras quiebras en cadena y la pérdida de la reputación y, por tanto, de la confianza. Como en ocasiones algunas personas trataban de ocultar una quiebra, "los comerciantes no tenían más recurso que prestar gran atención a la rumorología" ${ }^{97}$ Lo expuesto por Lamikiz se manifiesta también en el comercio del siglo XIX; aunque el autor se concentra en el comercio atlántico de larga distancia, las pesquisas que alimentan el presente artículo muestran fenómenos parecidos en el ámbito del comercio local.

La exposición de un último caso, de un cliente regular de los comerciantes Uribe Ruiz, ilustra lo antedicho. Laureano Gutiérrez, un pequeño comerciante de La Ceja (Antioquia), compraba mercancías de contado a los Uribe desde 1884 y, por lo menos, hasta 1904. Hacía pedidos de acero y hierro, seda, merino, coleta, cobijas e hilos. Sin embargo, en mayo de 1892, escribió muy preocupado a los comerciantes

\footnotetext{
${ }_{93}^{93}$ Sociedad de Beneficencia de Bogotá 9-11.

${ }^{94}$ Xabier Lamikiz, "Un "cuento ruidoso": confidencialidad, reputación y confianza en el comercio del siglo XVIII", Obradoiro de Historia Moderna 16 (2007): 113-142. Xabier Lamikiz, "Social capital, networks and trust in early modern long-distance trade. Acritical appraisal", Merchants and trade networks in the Atlantic and the Mediterranean, 1550-1800: Connectors of commercial maritime systems (London: Routledge, 2017) 39-61. Xabier Lamikiz, "Patrones de comercio y flujo de información comercial entre España y América durante el siglo XVIII”, Revista de Historia Económica 25.2 (2007): 231-258.

${ }^{95}$ Lamikiz, "Un "cuento ruidoso" 123.

${ }^{96}$ Lamikiz, "Un "cuento ruidoso" 117.

${ }^{97}$ Lamikiz, "Un "cuento ruidoso" 122.
} 
Estanislao Uribe y Rafael Duque, de Rionegro (Antioquia), para esclarecer un asunto que podría arruinar su reputación. Explicaba que no era verdad que él no tuviera con qué cubrir sus deudas o que estuviera a punto de entrar en quiebra; de hecho, tenía fincas con las que responder. Esperaba que no desconfiaran de él y que hicieran caso omiso de los rumores sobre su situación económica. Apuntaba que dichos comentarios se debían a que había bebido un tósigo y explicaba:

[...] Debido a que estuve tomando licor dos días largos, casi sin tomar alimento, se me debilitó el cerebro y me entró la idea de tomar narcótico, lo que efectué, casi sin conciencia de lo que hice. Esto fue lo que pasó y nada más, no hubo ni hay tal quiebra, ni tal pena moral, ni nada. A ustedes y a todos los demás que me han confiado sus intereses con tan buena voluntad y con tanta confianza, debo corresponderles en la misma moneda; así es que ningún cuidado tengan. Tengan la bondad de guardar absoluta reserva de esta carta $\left[\ldots . . .^{98}\right.$

Por supuesto, no todas las relaciones entre comerciantes y clientes terminaban bien. Algunos aceptaban que no podían pagar y esperaban que se ejecutara su hipoteca. Sin embargo, la mayoría deseaba conservar las buenas relaciones, tener una buena imagen o recuperar la confianza que habían alcanzado. ${ }^{99} \mathrm{En}$ suma, las relaciones de los comerciantes mayoristas con los clientes implicaban una serie de compromisos legales y morales. La información y la confianza eran cruciales para entrar en negocios y para presionar o tomar acciones cuando fuera necesario.

\section{Conclusiones}

La descripción de las relaciones entre compradores de mercancías importadas y comerciantes mayoristas muestra que quienes sustentaban una buena parte del negocio de importación eran clientes ubicados en pueblos. Es cierto que los importadores hacían ventas al por mayor a otros comerciantes y tenderos, pero también abastecían a quienes adquirían artículos de manera esporádica o irregular. En el mercado de bienes extranjeros participaban personas que combinaban diferentes actividades económicas de mediana importancia, como cultivar una parcela, sacar oro y plata de minas o vender propiedades y animales. La venta de mercancías se constituía en un complemento de dichas actividades. Como muestra la carta de Ignacio Uribe de 1887, no todos los clientes tenían una reputada economía, pues Uribe recomendaba a alguien a quien consideraba pobre, pero que en todo caso podría responder por unos "chismesitos" (sic). ${ }^{100}$

La relación entre clientes y comerciantes estaba mediada por acciones coercitivas formales e informales. Las primeras estaban representadas por leyes e instrumentos legales; las segundas por las ideas sobre las conductas sociales que debían regir los negocios, como el honor y la honradez. De ahí que el cuestionamiento

\footnotetext{
${ }^{98}$ AJMUU-196, CR, 1892-1893, ff. 7-8.

${ }^{99}$ AJMUU-179, CR, 1853-1885, ff. 10-11. AJMUU-22, CR, 1893, ff. 44-45. AJMUU-24, CR, 1894-1896, f. 80. AJMUU-112, CR, 1898, ff. 56-57, 89. AJMUU-113, CR, 1899.

${ }^{100}$ Carta enviada por Ignacio Uribe desde Neira a los comerciantes José María Uribe e Hijos y Rafael Duque en Rionegro, 10 de octubre de 1887. AJMUU-9, CR, 1887, f. 76.
} 
y el rumor se convirtieran en mecanismos de control. Los comerciantes mayoristas se amparaban en estas acciones para presionar a sus compradores en el cumplimiento de las obligaciones comerciales. En efecto, la presión social que ejercían por medio del manejo de la información les daba un margen de acción amplio contra posibles infractores de los acuerdos mercantiles. Al mismo tiempo, sin embargo, los comerciantes debían satisfacer unas demandas de consumo de sus compradores relativas a precios, calidad y gustos. También los compradores podían demorar los pagos de sus contados alegando mil excusas o circunstancias extraordinarias y, muy a pesar de las preferencias de los comerciantes de recibir dinero "constante y sonante", los clientes recurrían al trueque y al pago en especie, de manera que las relaciones entre estos dos actores no eran verticales.

Otros aspectos sobre la estructura comercial de la época que destaca este artículo fueron, por una parte, que la confianza era el fundamento básico de los negocios mercantiles, aun cuando existía un marco institucional legal. La confianza se basaba en recomendaciones personales, en la información recabada por diferentes medios y en el comportamiento crediticio, privado y público de las personas. Por otra parte, aunque ha sido usual afirmar que el crédito se hacía sobre todo con el sistema de cobro de los tres seises, había otros sistemas de plazos que respondían al valor del crédito, al historial crediticio de los clientes y a las circunstancias favorables o desfavorables determinadas por el contexto político y económico.

Habría que subrayar la necesidad de investigar las relaciones cotidianas que se daban entre diversos actores económicos con el propósito de comprender mejor la estructura socioeconómica del siglo XIX colombiano. Si solo se plantean problemas referidos a grupos con poder económico, como los comerciantes importadores, sin ahondar en la compleja trama de estrategias, negociaciones y vínculos que tenían con otros actores se estaría proponiendo una versión limitada de la historia. De hecho, la correspondencia comercial y personal de los comerciantes con sus clientes es una fuente imprescindible para comprender aspectos sociales, como los valores sobre los que se basaban las relaciones económicas.

Por supuesto, un análisis del fenómeno desde la teoría sociológica y antropológica a través de fuentes como la correspondencia y de otras, como los procesos judiciales por quiebras o por el incumplimiento de los acuerdos comerciales, ayudaría a comprender mejor el tema de las relaciones entre clientes y comerciantes descrito en este artículo desde una perspectiva micro, artículo que se constituye, sobre todo, en un invitación investigativa. 


\section{Bibliografía}

\section{Fuentes primarias}

\section{Fuentes de archivo}

Archivo Histórico de Antioquia, Fondo República, Hacienda Provincial de Antioquia, Derechos de consumo.

Archivo Histórico Municipal de Manizales, Fondo Notarial.

Archivo Mamerto García Montoya, Biblioteca Nacional de Colombia,

Archivo José María Uribe Uribe, Centro Cultural Biblioteca Luis Echavarría Villegas, Universidad EAFIT, Sala de Patrimonio Documental.

\section{Prensa}

Bureau of the American Republics, Colombia. Washington, bulletin No. 33, 1892.

Revista Mercantil. Órgano de la ajencia de negocios i de la casa de comercio Nicolas Esguerra (Bogotá) 1878.

\section{Fuentes secundarias}

\section{Libros}

Botero, María Mercedes. La ruta del oro. Una economía primaria exportadora. Antioquia 1850-1890. Medellím: Fondo Editorial Universidad EAFIT, 2007.

Castro Carvajal, Beatriz, editora. Historia de la vida cotidiana en Colombia. Bogotá: Editorial Norma, 1996.

Colombia. Código de comercio: 1 de junio de 1853. Bogotá: s.e, 1853.

Dávila, Carlos, coord. Empresas y empresarios en la historia de Colombia, siglos XIX-XX: una colección de estudios recientes. Bogotá: Editorial Norma, 2003.

García, Rodrigo de Jesús, coord. Élites, empresarios y fundadores: los casos de Antioquia y sur de Bolívar (Colombia), y el Tucumán colonial (Argentina). Medellín: Universidad de Antioquia, Centro de Investigaciones de Ciencias Sociales y Humanas, 2003.

Gaviria Virginia, Diana Gil y Juan Esteban Vélez. Las sociedades civiles comerciales y de minas inscritas en los juzgados de Antioquia entre 1887 y 1934, una historia de la actividad societaria de la región. Medellín: Editorial Universidad EAFIT, 2020. 
Compradores de chismes y otras mercancias: las relaciones entre clientes y comerciantes...

Gosselman, Carl August. Resa i Colombia: Aren 1825 och 1826. Nyköping: Tryckt Hos P. E. Winge, 1828.

Kastos, Emiro. Emiro Kastos Colección de artículos escogidos. Bogotá: Imprenta de Pizano i Pérez, 1859.

Palacios, Marco y Frank Safford. Colombia, país fragmentado, sociedad dividida. Bogotá: Uniandes, 2011.

Posada Carbó, Eduardo. El caribe colombiano: una historia regional, 1870-1950. Bogotá: Banco de la Republica, 1998.

Tovar Pinzón, Hermes. Que nos tengan en cuenta. Colonos, empresarios y aldeas: Colombia 1800-1900. Bogotá: Colcultura, 1995.

Twinam, Ann. Mineros, comerciantes y labradores: las raices del espíritu empresarial en Antioquia: 1763-1810. Medellín: Fondo Rotatorio de Publicaciones FAES, 1985.

Uribe Ángel, Manuel. Geografía general del Estado de Antioquia en Colombia. Medellín: Autores Antioqueños, 1985.

Uribe de Hincapié, María Teresa y Álvarez, Jesús María. Raíces del poder regional: el caso antioqueño. Medellín: Editorial Universidad de Antioquia, 1998.

Valencia Llano, Albeiro. Colonización, fundaciones y conflictos agrarios Gran Caldas y Norte del Valle. Manizales: Artes Gráficas Tizán, 2000.

\section{Capítulos de libros}

Álvarez Morales, Víctor. "Empresarios pueblerinos de Antioquia. El caso de José María "Pepe" Sierra S. 1846-1921". Élites, empresarios y fundadores. Los casas de Antioquia y sur de Bolivar (Colombia) y el Tucumán (Argentina), Ed. Rodrigo García. Medellín: CISH-Colciencias, 2003.

Caro, J. E. "Sobre el lujo". Sociedad de Beneficencia de Bogotá, El hombre honrado y laborioso. Bogotá: Imprenta de J. A. Culla, 1842.

Castro, Beatriz. "La vida pública en las ciudades republicanas". Historia de la vida cotidiana en Colombia, Ed. Beatriz Castro Carvajal. Bogotá: Editorial Norma, 1996.

Deas, Malcom. "La política en la vida cotidiana republicana”. Historia de la vida cotidiana en Colombia, Ed. Beatriz Castro Carvajal. Bogotá: Editorial Norma, 1996. 
Jiménez, Michael F. "La vida rural cotidiana". En Historia de la vida cotidiana en Colombia, Ed. Beatriz Castro Carvajal. Bogotá: Editorial Norma, 1996.

Lamikiz, Xabier. "Social capital, networks and trust in early modern long-distance trade. Acritical appraisal". Merchants and trade networks in the Atlantic and the Mediterranean, 1550-1800: Connectors of commercial maritime systems. London: Routledge, 2017.

Londoño Vega, Patricia. "La vida diaria: usos y costumbres". Historia de Antioquia, Ed. Jorge Orlando Melo. Medellín: Suramericana de Seguros, 1988.

Meisel, Adolfo. "Bajo el signo del cóndor: empresas y empresarios en el Caribe colombiano, 1982-2009”. ¿Por qué perdió la costa caribe el siglo XX? Y otros ensayos. Cartagena: Banco de la República, 2011.

Safford, Frank. "Economía y clases sociales en el siglo XIX". Aspectos Polémicos de la Historia Colombiana del Siglo XIX, memoria de un seminario. Bogotá: Fondo Cultural Cafetero, 1983.

\section{Artículos de revistas}

Botero, María Mercedes. "Casas comerciales y circuitos mercantiles en Antioquia: 1842-1880”. Revista Sociedad y Economía 12 (2007): 93-114.

Carreño, Clara Inés. "Puertos locales y bienes de consumo: importación de mercancías finas en Santander, Colombia, 1870-1900". América Latina en la Historia Económica 22.1 (2015): 85-114. http://www.scielo.org.mx/scielo.php?script=sci arttext\&pid $=$ S1405-22532015000100004 (25/07/2020)

Duque Castro, María Fernanda. "Comerciantes y empresarios de Bucaramanga (1857-1885): una aproximación desde el neoinstitucionalismo". Historia crítica 29 (2005): 149-184. https://doi.org/10.7440/histcrit29.2005.07 (25/07/2020)

Forestier, Albane. "Risk, kinship and personal relationships in late eighteenth-century West Indian trade: The commercial network of Tobin \& Pinney". Business History 52.6 (2010): 912-931. https://doi.org/10.1080/00076791.2010.511182 $(25 / 07 / 2020)$

Greif, Avner. "Contract Enforcement and Institutions among the Maghribi Traders: Refuting Edwards and Ogilvie". SSRN (2008): 1-30. https://ssrn.com/ abstract $=1153826$ or http://dx.doi.org/10.2139/ssrn.1153826 (3/12/2020)

Greif, Avner. "Teoría de juegos e historia de la empresa". Historia empresarial 812 (2004): 9-26. http://ebour.com.ar/ensayos_meyde/Avner\%20Greif\%20 -\%20Teoria\%20de\%20Juegos\%20e\%20Historia\%20de\%20la\%20Empresa.pdf $(3 / 12 / 2020)$ 
Compradores de chismes y otras mercancias: las relaciones entre clientes y comerciantes...

Lamikiz, Xabier. "Patrones de comercio y flujo de información comercial entre España y América durante el siglo XVIII". Revista de Historia Económica 252 (2007): 231-258. https://dialnet.unirioja.es/servlet/articulo?codigo=2486216 $(25 / 07 / 2020)$

Lamikiz, Xabier. "Un “cuento ruidoso": confidencialidad, reputación y confianza en el comercio del siglo XVIII". Obradoiro de Historia Moderna 16 (2007): 113142. DOI: $10.15304 /$ ohm.16.541 (25/07/2020)

Mejía Cubillos, Javier. "Vínculos interregionales en la economía colombiana del siglo XIX: el empresariado de la costa Caribe en el interior del país, 1840-1880". Economía y Región 8.1 (2014): 197-201. https://revistas.utb.edu.co/index.php/ economiayregion/article/view/81 (25/07/2020)

Mejía Cubillos, Javier. "Crecimiento económico de largo plazo en Antioquia, Colombia: Estimación del PIB. 1800-1913". Cuadernos de Economía 34-66 (2015): 507-544. https://doi.org/10.15446/cuad.econ.v34n66.44418 (4/12/2020)

Mejía Cubillos, Javier. "El auge económico antioqueño del siglo XIX desde un enfoque de desarrollo económico local”. Ensayos de economía 45 (2014): 11-34. https://revistas.unal.edu.co/index.php/ede/article/view/50429 (4/12/2020)

Otero-Cleves, Ana María. ““'Jeneros de gusto y sobretodos ingleses” el impacto cultural del consumo de bienes ingleses por la clase alta bogotana del siglo XIX". Historia crítica 38 (2009): 20-45. https://doi.org/10.7440/histcrit38.2009.03 $(25 / 07 / 2020)$

Otero-Cleves, Ana María. "Foreign Machetes and Cheap Cotton Cloth: Popular Consumers and Imported Commodities in Nineteenth-Century Colombia”. Hispanic American Historical Review 97-3 (2017): 423-456. DOI: 10.1215/00182168$3933828(25 / 07 / 2020)$

Patiño Millán, Beatriz. "Los comerciantes de Medellín, 1763-1810”. Utopía Siglo XXI 2.8 (2002): 111-145.

Rhenals Doria, Ana Milena y Francisco J. Flórez Bolívar. "Distintos sujetos bajo un mismo predicado: reflexión historiográfica sobre la historia empresarial en el Caribe colombiano". El Taller de la Historia III.3 (2011): 139-160. DOI: 10.32997/2382-4794-vol.3-num.3-2011-672 (25/07/2020)

Uribe de Hincapié, María Teresa. "Bajo el signo de mercurio: la influencia de los comerciantes de Medellín en la segunda mitad del siglo XIX". RAED Revista Antioqueña de Economía y Desarrollo 30 (1989): 39-50.

Valencia Llano, Alonso. "El chisme y el escándalo en la sociedad colonial”. Estudios Sociales 3 (1988): 35-48. 


\section{Tesis, ponencias y otros inéditos}

Ospina, Marta Cecilia. "Un siglo de trabajo artesanal en Antioquia”. Tesis de pregrado en Historia, Universidad de Antioquia, 1995.

Safford, Frank. "Commerce and Enterprise in Central Colombia, 1821-1870". Thesis $\mathrm{PhD}$, Columbia University, 1965.

\section{Publicaciones en Internet}

“Carta Jeográfica de los Estados Unidos de Colombia Antigua Nueva Granada construida de orden del Gobierno Jeneral con arreglo a los trabajos corográficos del Jeneral A. Codazzi i a otros documentos oficiales por Manuel Ponce de León..."de 1864. Consultada el 26 de marzo de 2020, https://catalogoenlinea. bibliotecanacional.gov.co/custom/web/content/mapoteca/fmapoteca_17 fagn_16/fmapoteca_17_fagn_16.html (25/07/2020)

“Chisme" https://dle.rae.es/chisme?m=form (25/07/2020)

Melo, Jorge Orlando. "Historia de la población y ocupación del territorio colombiano". Colombia es un tema (1990) http://www.jorgeorlandomelo.com/histpobla.htm $(25 / 07 / 2020)$ 